\title{
Formation of recommendations for the selection of types of connections for different types of crossroads based on the generalized imitation model
}

\author{
Aleksandr Novikov ${ }^{1, *}$, Sergey Eremin ${ }^{2}$, and Andrei Kulev ${ }^{1}$ \\ ${ }^{1}$ Orel State University, 302026 Orel, Komsomolskaya st. 95, Russian Federation \\ ${ }^{2}$ Krasnoyarsk City Administration, 660049 Krasnoyarsk, Karl Marks str., 93, Russian Federation
}

\begin{abstract}
The paper deals with the issues of the transport network imitation modeling. Preliminary the authors analyzed the main modeling systems, which include Aimsun, MATSim, Anylogic, PTV VISUM and others. All these instrumental tools have the ability to form an arbitrary structure of the transport network. The research showed, however, for the small sections of the street road network (SRN), such as the crossroad, the Anylogic system is more efficient and makes it possible to parameterize the model, which can be used to model various structures of the crossroad. In this regard, the paper proposes a generalized model of the crossroad and, based on its modeling, gives recommendations for choosing the type of crossroads at different intensities of traffic flows.
\end{abstract}

\section{Introduction}

In recent years, the Russian Federation has begun the widespread use of transport models which allow predicting traffic intensity more accurately.

As a rule, when forming programs for the development of the street-road network (SRN), the principle remains the same - in accordance with the forecast, the calculated traffic intensity is accepted, which is the rationale for the parameters of the roadway.

In other words, the reconstruction of the streets usually implies the expansion of the roadway, or its preservation in the previous parameters in case of impossibility of its expansion.

Herewith, new streets are designed with a margin of bandwidth, based on its growth. At the same time, the increase in traffic intensity is taken as a fact that does not imply any impact on this process in the design framework. As a result, the development of SRN is carried out under conditions of an uncontrolled increase in traffic intensity and does not take into account feedback.

The basis for modeling traffic flows is software and tools (Aimsun, MATSim, Anylogic, PTV VISUM and others) that allow creating a SRN structure, characteristics of vehicles, as well as the parameters of their movement in the system [1-10]. So, there is the

\footnotetext{
* Corresponding author: novikovan57@gmail.com
} 
possibility of high-speed simulation of dynamic and static traffic flows of vehicles in the Aimsun tool environment, using microscopic, mesoscopic and hybrid modeling (Figure 1).

Levels of modeling

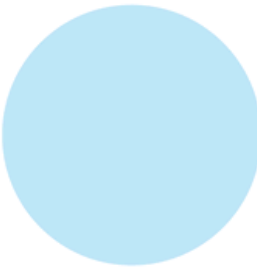

Macroscopic level

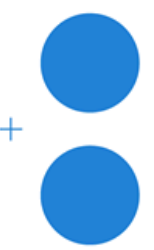

Mesoscopic level

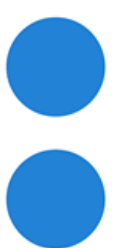

(1)

Microscopic level
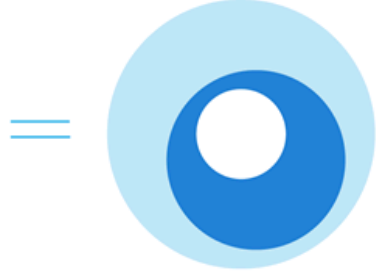

3 in 1

Fig. 1. Levels of modeling.

The use of mathematical models in developing traffic management projects is possible at the following stages:

1. Getting the source data to solve the problems of the project;

2. Variant modeling for the rapid assessment of the effectiveness of decisions;

3. Analysis of the effectiveness of decisions made at the final stage of work or during the audit of design decisions.

Taking into account the features of mathematical methods of various classes of models, their applicability to the designated stages is determined by Table 1.

Table 1. Application areas of traffic modeling.

\begin{tabular}{|c|c|c|c|c|}
\hline \multirow{2}{*}{\multicolumn{2}{|c|}{$\begin{array}{c}\text { Class of a } \\
\text { mathematical } \\
\text { model }\end{array}$}} & \multicolumn{3}{|c|}{ Stage of work } \\
\hline & & \multirow{2}{*}{$\begin{array}{c}\text { Getting the } \\
\text { source data } \\
+\end{array}$} & \multirow{2}{*}{$\begin{array}{c}\begin{array}{c}\text { Variant } \\
\text { design }\end{array} \\
+\end{array}$} & \multirow{2}{*}{$\begin{array}{c}\text { Analysis of the effectiveness of } \\
\text { decisions, audit of design decisions }\end{array}$} \\
\hline Mron & Analytical & & & \\
\hline мыасro & Imitation & + & + & - \\
\hline \multirow{2}{*}{ Meso } & Analytical & + & + & + \\
\hline & Imitation & + & + & + \\
\hline \multirow{2}{*}{ Micro } & Analytical & - & + & + \\
\hline & Imitation & - & + & + \\
\hline
\end{tabular}

Models are classified by accuracy classes according to Table 2.

According to accuracy classes, models are classified according to Table 2.

Table 2. Accuracy classes of modeling types.

\begin{tabular}{|l|l|l|l|}
\hline Model classification & Macro & Meso & Micro \\
\hline Analytical & Low & Average & High \\
\hline Imitation & Average & High & Very high \\
\hline
\end{tabular}

These accuracy classes uniquely describe the requirements for the use of models in the context of the classification of projects for organizing traffic, and allow determining the accuracy matrix (Table 3). 
Table 3. Accuracy matrix of modeling methods

\begin{tabular}{|c|c|c|c|c|c|c|}
\hline № & $\begin{array}{l}\text { Scale and } \\
\text { shape }\end{array}$ & $\begin{array}{c}\text { Operating } \\
\text { time }\end{array}$ & Functionality & $\begin{array}{l}\text { Territory } \\
\text { type }\end{array}$ & $\begin{array}{l}\text { Traffic } \\
\text { control } \\
\text { system }\end{array}$ & $\begin{array}{c}\text { The } \\
\text { participants of } \\
\text { the traffic }\end{array}$ \\
\hline 1 & Areal & $\begin{array}{l}\text { For the } \\
\text { period of } \\
\text { the facility } \\
\text { operation }\end{array}$ & $\begin{array}{l}\text { Street-road } \\
\text { network } \\
\text { facilities }\end{array}$ & $\begin{array}{c}\text { Roads } \\
\text { outside } \\
\text { settlements }\end{array}$ & $\begin{array}{c}\text { With } \\
\text { control } \\
\text { systems }\end{array}$ & $\begin{array}{l}\text { All participants } \\
\text { of the traffic }\end{array}$ \\
\hline 2 & Linear & $\begin{array}{l}\text { In the long } \\
\text { term }\end{array}$ & $\begin{array}{c}\text { Industrial and } \\
\text { civil } \\
\text { construction } \\
\text { facilities }\end{array}$ & $\begin{array}{c}\text { SRN of } \\
\text { settlements }\end{array}$ & $\begin{array}{l}\text { Without } \\
\text { control } \\
\text { systems }\end{array}$ & $\begin{array}{l}\text { Selective list of } \\
\text { participants in } \\
\text { the traffic }\end{array}$ \\
\hline 3 & Point & $\begin{array}{l}\text { For the } \\
\text { short term }\end{array}$ & & & & \\
\hline
\end{tabular}

In the process of modeling and optimization in MATSim, there are five main stages: the formation of initial demand; performance of scenario; calculation of efficiency; adaptation of scenarios to the traffic situation; analysis (Figure 2).

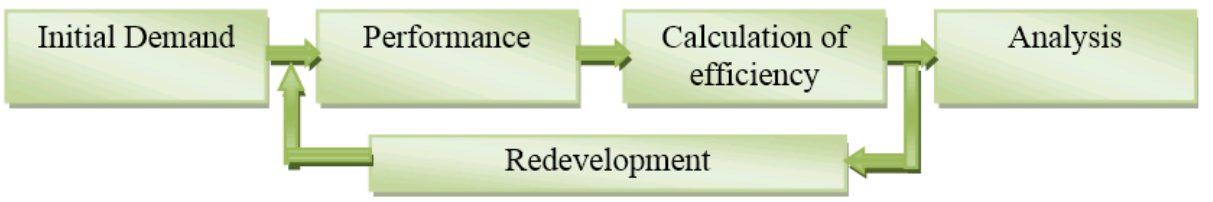

Fig. 2. Levels of modeling

However, we should note that the instrumental tools are mainly aimed at forming fairly adequate models of SRN and the spectrum of methods for planning experiments on imitation models is not used enough, taking into account a very large number of variable factors and non-stationary processes of development of traffic situations.

\section{Formal description of elements and construction of a transport network model}

In all instrumental environments that allow modelling of traffic flows, the initial step is to create a road network. A realistic road network can be created using satellite imagery. The libraries of modelling environments contain a large number of ready-made objects of road infrastructure (shops, gas stations, trees, bus stops, parking lots, etc.) that will help to quickly give the creating road network recognizable features with the existing section of the real road.

For each drawn section of the road, the number of main traffic lanes, the presence of one-way traffic, the number of oncoming traffic lanes and the width of the dividing lane are set; there are additional parameters for adjusting the height and inclinations of the road. Important features of setting traffic flow parameters are the appointment of traffic routes, conflict points. (Figure 3). 


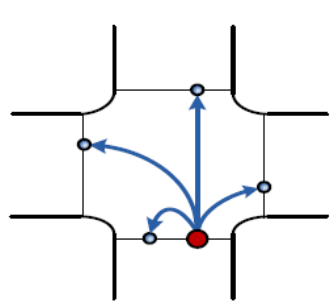

a)

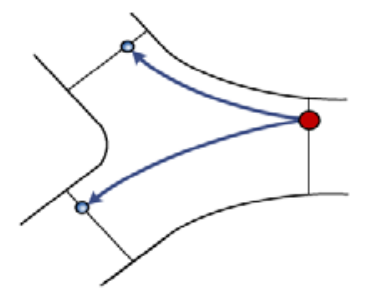

c)

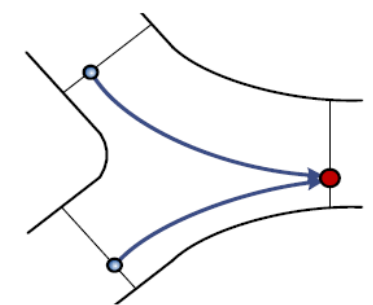

b)

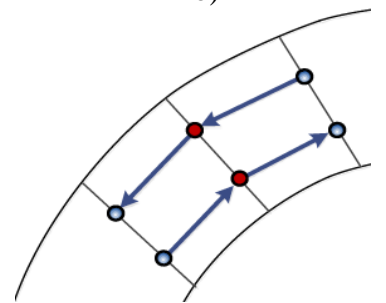

d)

Fig. 3. Patterns of SRN: a) routes at the crossroad; b) the merger of traffic flows; c) separation of traffic flows; d) two-way traffic.

These elements are the components of the zone control system. (Figure 4)

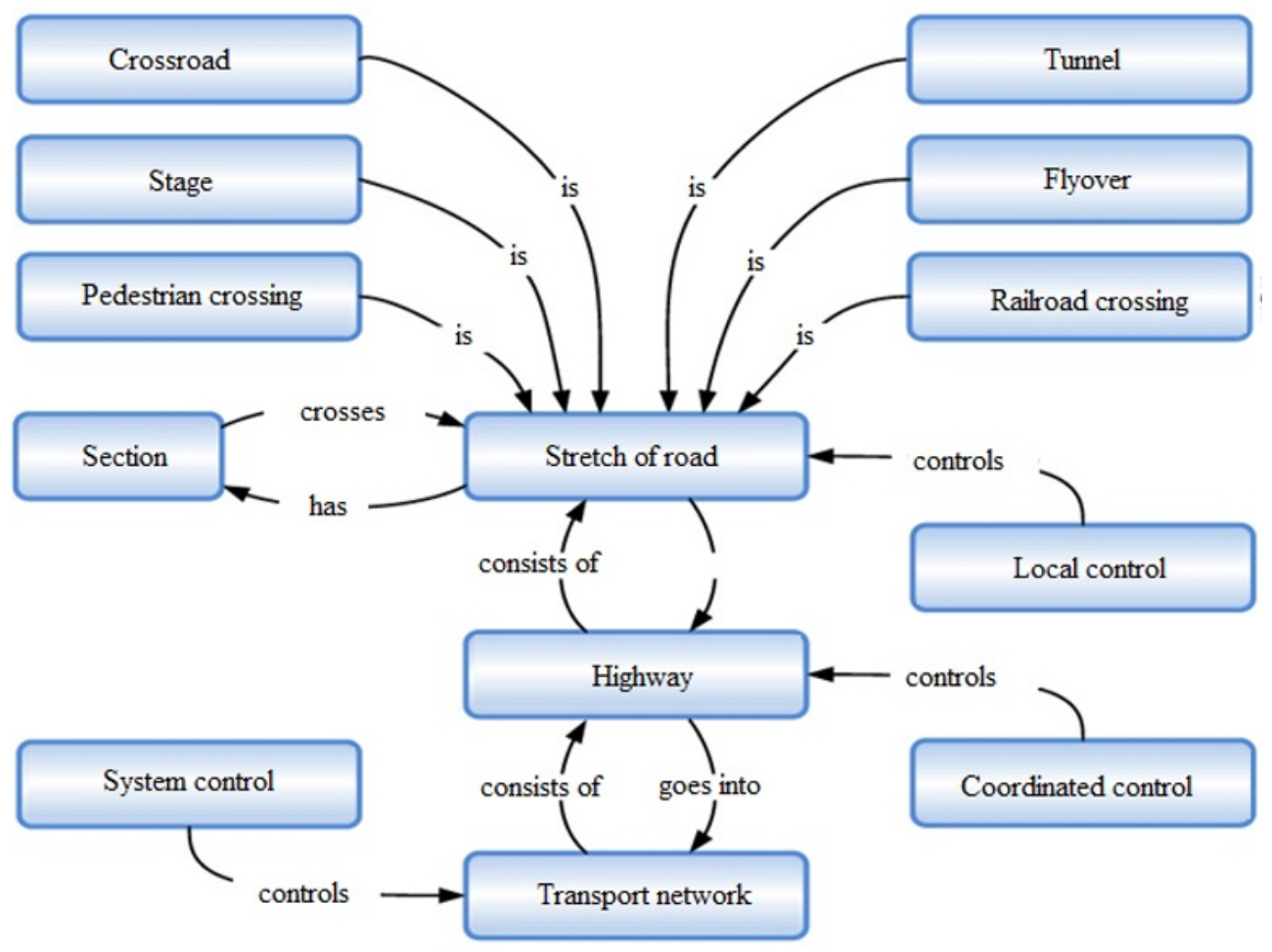

Fig. 4. Decomposition of spatial zones and types of control.

Sign decomposition characterizes the zone by the sign of influence exerted by an object of one class of vehicles on objects of this or that class, and leading to a change in the parameters of transport processes (Figure 5). The influence can be positive and negative, has power and range [11]. 


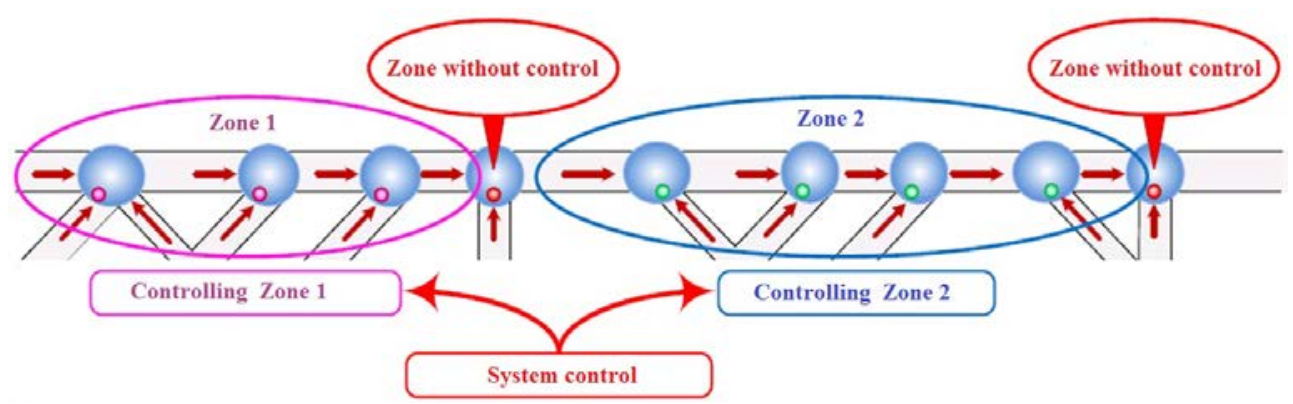

Fig. 5. Coordinated and system control zone pattern.

In forming the characteristics of vehicles for each generator of machines, length, initial speed, preferred speed, maximum acceleration, maximum braking are used. The intensity of creating a car at the beginning of the road or the task of a time interval is also set. Change in the probabilities of route formation is possible [12-14].

As part of the statistics collected, the average speed, stop and traffic reopening, the average time spent in the transport system, the number of inputs and outputs from the transport system by the number of machines generated and left the system are used.

\section{Planning the experiment on the imitation model}

In general, there are a lot of model parameters for a street network graph. In this regard, it is necessary to use the entire spectrum of experimental design methods.

The main criterion for optimality in the construction of plans is the independence of the columns of the plan matrix, which makes it possible to independently calculate the regression coefficients. In the general case, the orthogonality of $\mathrm{x}_{0}$ and $\mathrm{x}_{\mathrm{i}}{ }^{2}$ can be obtained by transforming $\hat{x}_{i}^{2}=x_{i}^{2}-\sum_{j=1}^{N} x_{j i}^{2} / N=x_{i}^{2}-\bar{x}_{i}^{2}$, which gets the following result $\sum_{j=1}^{N} x_{j 0}^{2} \cdot \hat{x}_{j i}^{2}=\sum_{j=1}^{N} x_{j 0}^{2}\left(x_{j i}^{2}-\sum_{j=1}^{N} x_{j i}^{2} / N\right)=0$. Herewith, the coordinate of the $\alpha$ - star point for the analyzed independent variables is selected based on the orthogonality condition.

Within the framework of orthogonal compositional planning, and accordingly the processing of experimental results, there are some features. So, the variance of the estimates of the regression coefficients has different values for each coefficient $S_{b_{i}}^{2}=S_{y}^{2} /\left(P \cdot \sum_{j=1}^{N} z_{j i}\right)$, where P represents the number of parallel tests, and the denominator of the expression for different coefficients is also different.

Criteria for assessing traffic flow conditions are bandwidth, service level and others (Figure 6). The crossroad capacity is used only for automobile vehicles and indicates the number of vehicles that can travel through the crossroad per unit of time. 


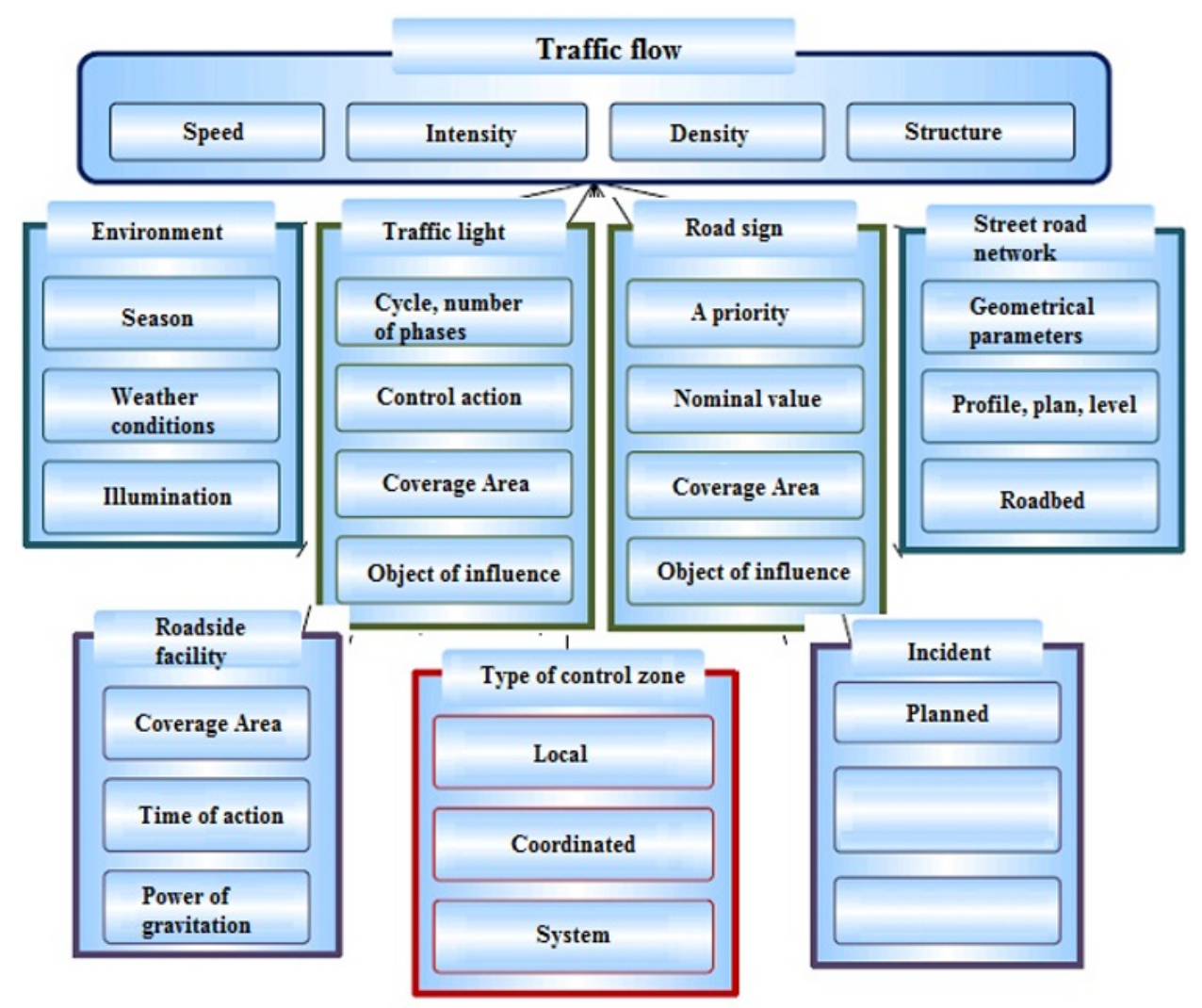

Fig. 6. Factors and characteristics of traffic flow.

\section{Criteria for Selecting Crossroad Type}

The main types of crossroads are a junction, an intersection, an intersection with a circular motion and an intersection spaced into two junctions. The kind of priority is of great importance [15-16]:

1. Crossroads without traffic lights: a. Crossroads of equal roads, b. Crossroads of unequal roads, c. Roundabout

2. Crossroads with traffic lights.

The basis for selecting the crossroad scheme is the uniformity of the design, construction and operation. The crossroad should be: 1. Recognizable, 2. Visible, 3. Understandable (recognizable), 4. Convenient for passing, 5. Convenient for walking.

According to the Decree of the Government of the Russian Federation No. 1521 of December 26, 2014, for designing the geometric parameters of road and street infrastructure, as well as crossroads and junctions, it is mandatory to be guided by two regulatory documents: Code of practice. Car roads. Updated edition of Building Code 2.05.02-85 *; Set of rules 42.13330.2011. Set of rules. Urban planning. Planning and development of urban and rural settlements. Updated edition of Building Code 2.07.01-89 *.

However, Set of rules 34.13330.2012 regarding design of crossroads and junctions of highways takes into account only suburban highways. Thus, Set of rules 42.13330.2011 is responsible for the design of intersections and junctions in the city. But there is no information about intersection patterns. 
We can see intersection schemes for designing in urban conditions only in the "Recommendations for the design of streets and roads of cities and rural settlements", which were developed in addition to Set of rules 42.13330.2011 [12].

\section{Development of a generalized imitation model of the crossroad}

As part of the verification of recommendations for various intersection options, a generalized imitation model was implemented in Anylogic environment (Figure 7).
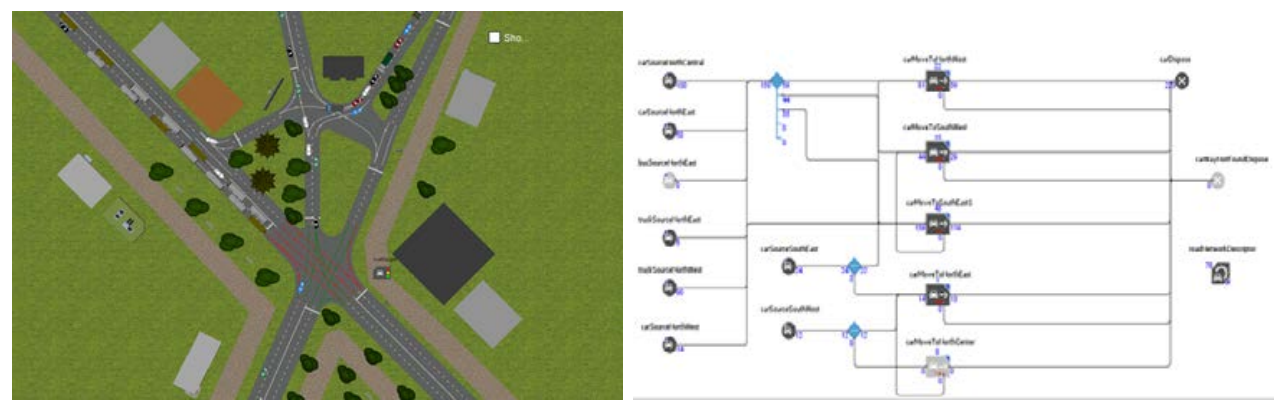

Fig. 7. Generalized model of the crossroad structure.

For each model of the crossroad (Figure 8), an imitation modeling was performed and the average delay time of vehicles at the crossroad in each direction of movement was found.
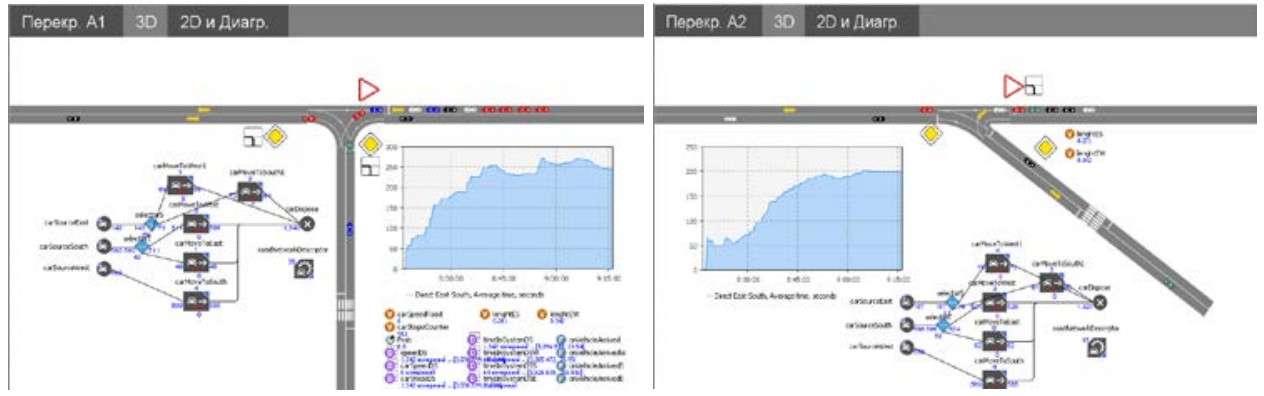

Fig. 8. Model parameterization for various crossroads.

A variant of the circular motion model with a variable radius was considered separately. As a result of the simulation, the values of the change in the speed of movement were obtained.

\section{Conclusion}

As a result of modeling and analysis of generally accepted recommendations for crossroads of equal roads, unequal roads, with roundabouts and traffic lights, the following advantages and disadvantages, we formed the advantages and disadvantages of various types of intersections and junctions (Table 4), areas of predominant use of various types of intersections (Table 5), criteria for selecting an intersection depending on the category of intersecting streets (Table 6). 
Table 4. Advantages and disadvantages of various types of crossroads.

\begin{tabular}{|c|c|c|c|c|}
\hline \multirow[b]{2}{*}{ Indicator } & \multicolumn{4}{|c|}{ Type of crossroad } \\
\hline & 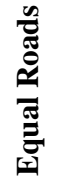 & 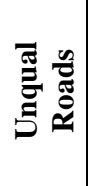 & 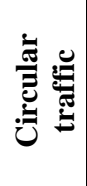 & 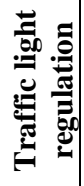 \\
\hline Significant reduction in speed & $+/-$ & - & + & - \\
\hline No traffic accidents due to high speed & $+/-$ & - & + & - \\
\hline The ability to coordinate traffic & - & - & - & + \\
\hline No delays for public transport & - & $+/-$ & - & + \\
\hline Safe pedestrian crossing (with traffic light regulation) & - & - & - & + \\
\hline
\end{tabular}

Table 5. Application area of various types of crossroads.

\begin{tabular}{|c|c|c|c|c|}
\hline \multirow[b]{2}{*}{ Application area } & \multicolumn{4}{|c|}{ Type of crossroad } \\
\hline & 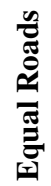 & 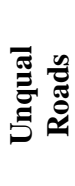 & 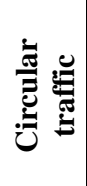 & 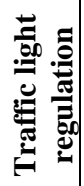 \\
\hline Intersections and junctions on two-lane roads & + & + & + & + \\
\hline $\begin{array}{l}\text { Intersections and junctions on roads with more than two lanes in each } \\
\text { direction }\end{array}$ & - & $+/-$ & + & + \\
\hline Driveways with equal priority & + & - & + & + \\
\hline
\end{tabular}

Table 6. The selection of intersection depending on the category of intersecting streets.

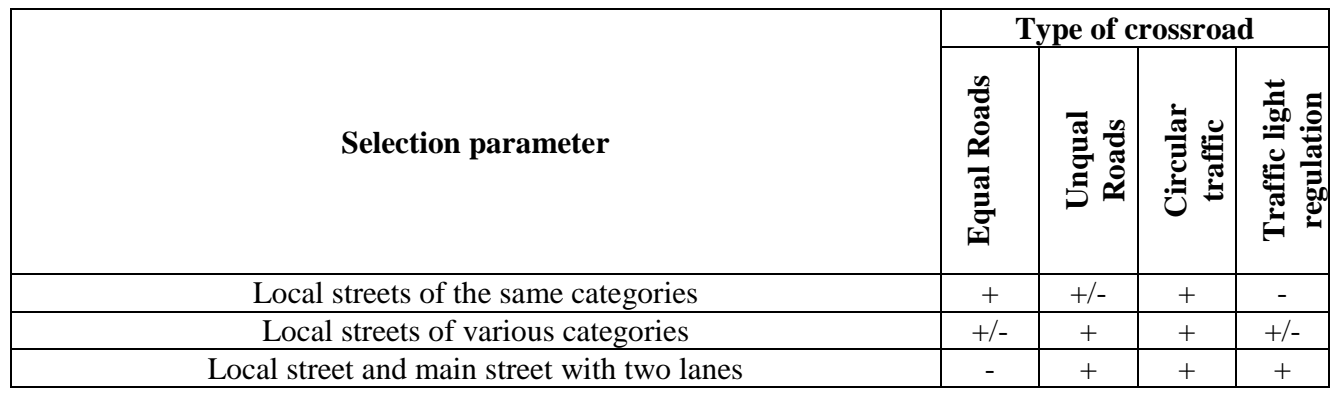

The use of imitation modeling tools made it possible to formulate basic recommendations on the use of various types of road intersections to solve specific problems of the street road network. It is advisable to design crossroads of equal roads at intersections and junctions on two-lane roads of local importance of the same categories or on driveways with equal priority; however, a number of drawbacks can be highlighted, such as the lack of coordination of traffic and safety problems when crossing the intersection. Crossing unequal roads is most relevant for intersections and junctions on two-lane roads of local importance of the same categories or at the intersection of local streets and a main street with two lanes. This type of intersection is characterized by an increased likelihood of traffic accidents at high speeds, inability to coordinate traffic and increased danger to pedestrians. The organization of roundabouts shows its effectiveness at intersections of all types of roads, but it can significantly reduce the speed and safety of the passage of the carriageway by pedestrians. Traffic light regulation makes it possible to coordinate road users and is characterized by the most acceptable indicators of road safety for pedestrians and the possibility of increasing the speed of public transport. 
The generated recommendations can be used in the design of the road network of cities and regions in order to eliminate the most important problems of traffic, increase communication speed and safety of participants in the transport process.

\section{References}

1. A.A Agasyants Razvitie seti avtomobil'nyh magistralej $v$ krupnejshih gorodah [Development of a network of highways in major cities], Transportno-gradostroitel'nye problemy: monografija [Transport and urban planning problems: monograph]. Moscow: Publishing house ASV, 248 p. (2010) (in Russian)

2. I.I. Lyubimov Model' avtotransportnoj seti regiona (na primere Orenburgskoj oblasti) [Model of the region's motor transport network (on the example of the Orenburg region). Bulletin of OSU, no 10 (129), pp. 32-37. (2011) (in Russian)

3. O.N. Larin Metodologija organizacii i funkcionirovanija transportnyh sistem regionov: monografija [Methodology of organization and functioning of transport systems of regions: monograph]. Ed. L.B. Mirotin. Cheljabinsk: South Ural State University, 205 p. (2007) (in Russian)

4. S.Yu. Olkhovsky Modelirovanie funkcionirovanija i razvitija marshrutizirovannyh sistem gorodskogo passazhirskogo transporta: monografija [Modeling the functioning and development of routed systems of urban passenger transport: monograph]. Omsk: Siberian State Automobile and Highway University, 138 p. (2001) (in Russian)

5. Software package for traffic planning and traffic management "PTV Vision®": an electronic resource. Access mode: http: //www. ptv-vision. ru. (in Russian)

6. V.M. Vlasov, A.N. Novikov, I.A. Novikov \& A.G. Shevtsova, "Definition of perspective scheme of organization of traffic using methods of forecasting and modeling", IOP Conference Series: Materials Science and Engineering (2018)

7. S.V. Zhankaziev, A.N. Novikov, A.I. Vorobyev, A.V. Kulev \& D.Y. Morozov "Definition of accuracy of qualitative correspondence matrixes for indirect traffic flow control and regulation", International Journal of Applied Engineering Research, vol. 12, no. 13, pp. 3653-3658 (2017).

8. S.V. Zhankaziev, A.N. Novikov, A.I. Vorobyev, A.V. Kulev, \& D.Y. Morozov "Efficiency of operation and functioning of the system of an indirect transport flow regulation and control", International Journal of Applied Engineering Research, vol. 12, no. 13, pp. 3645-3652 (2017).

9. A. Novikov, I. Novikov \& A. Shevtsova "Modeling of traffic-light signalization depending on the quality of traffic flow in the city", Journal of Applied Engineering Science, vol. 17, no. 2, pp. 175-181 (2019).

10. S.V. Dorokhin, A.N. Novikov, V.A. Zelikov, Y.V. Strukov, I.A. Novikov, A.G. Shevtsova \& D.V. Likhachev Investigation of methods for calculating duration of lightsignal regulation cycle. Paper presented at the Journal of Physics: Conference Series, , 1015(3) doi:10.1088/1742-6596/1015/3/032128 (2018).

11. V.M. Vlasov, A.N. Novikov, I.A. Novikov \& A.G. Shevtsova "Definition of perspective scheme of organization of traffic using methods of forecasting and modeling", IOP Conference Series: Materials Science and Engineering (2018).

12. N. Zagorodnikh, A. Novikov \& A. Yastrebkov "Algorithm and software for identifying accident-prone road sections", Transportation Research Procedia, pp. 817 (2018).

13. A. Novikov, V. Vasilyeva \& A. Shevtsova "Approaches to ensuring traffic safety for persons with reduced mobility", Transportation Research Procedia, pp. 540 (2018). 
14. D. Lomakin, E. Fabrichnyi \& A. Novikov "Improving the system of traffic management at crossings", Transportation Research Procedia, pp. 446 (2018).

15. A. Novikov, I. Novikov \& A. Shevtsova "Study of the impact of type and condition of the road surface on parameters of signalized intersection", Transportation Research Procedia, pp. 548 (2018).

16. N. Aleksandr, Z. Vladimir \& F. Anastasiya Dynamic traffic re-routing as a method of reducing the congestion level of road network elements. Journal of Applied Engineering Science, 16(1), 70-74. doi:10.5937/jaes16-15289 (2018) 